\section{Laminectomy alone versus fusion for grade 1 lumbar spondylolisthesis in 426 patients from the prospective Quality Outcomes Database}

TO THE READERSHIP: We report some errors in our recent article published in the Journal of Neurosurgery: Spine (Chan AK, Bisson EF, Bydon M, et al: Laminectomy alone versus fusion for grade 1 lumbar spondylolisthesis in 426 patients from the prospective Quality Outcomes Database. J Neurosurg Spine 30:234-241, 2019).

After publication, we found that some of the values presented in our statistical analyses were incorrect. Although these errors do not change the findings, the findings' statistical significance, or our conclusions, we appreciate the opportunity to correct the errors at this time and set the record straight.

Specifically, we would like to alert you of the following changes (all corrections marked in bold typeface):

Abstract, Results section, last sentence. The original sentence was "In adjusted analysis, fusion procedures were associated with superior 12-month ODI (OR 0.01, 95\% CI 0.0001-0.74; $\mathrm{p}=0.04)$."

Corrected, the sentence now reads: "In adjusted analysis, fusion procedures were associated with superior 12-month ODI $(\boldsymbol{\beta}-\mathbf{4 . 7 9}, \mathbf{9 5 \%} \mathrm{CI}-\mathbf{9 . 2 8}$ to $-\mathbf{0 . 3 1} ; \mathrm{p}=$ 0.04).

Page 5, Column 1, 1st full paragraph. Originally, the paragraph was presented as follows:

In adjusted multivariate analysis (Table 6), the addition of fusion was independently associated with superior ODI at the 12-month follow-up period (OR 0.01, 95\% CI $0.0001-0.74 ; \mathrm{p}=0.04)$. Additional factors significantly associated with 12-month ODI include BMI (OR 1.60, 95\% CI $1.23-2.08 ; \mathrm{p}=0.001$ ), education status (OR $0.02,95 \%$ CI $0.001-0.60 ; \mathrm{p}=0.02)$, employment status (OR 0.002 , 95\% CI 0.00005-0.10; $\mathrm{p}=0.002)$, and baseline ODI (OR $1.55,95 \%$ CI 1.36-1.77; $\mathrm{p}<0.001)$.

Corrected, the paragraph now states:

In adjusted multivariate analysis (Table 6), the addition of fusion was independently associated with superior ODI at the 12-month follow-up period $(\boldsymbol{\beta} \mathbf{- 4 . 7 9 , 9 5 \%} \mathrm{CI} \mathbf{- 9 . 2 8}$ to -0.31; $\mathrm{p}=0.04)$. Additional factors significantly associated with 12-month ODI include BMI $(\boldsymbol{\beta} \mathbf{0 . 4 7 , 9 5 \%} \mathbf{C I}$ 0.21 to 0.73; $\mathrm{p}=0.001)$, education status $(\boldsymbol{\beta} \mathbf{- 3 . 9 5}, \mathbf{9 5 \%}$ CI -7.38 to $-\mathbf{0 . 5 2} ; \mathrm{p}=0.02)$, employment status $(\boldsymbol{\beta}-\mathbf{6 . 1 0}$,
95\% CI -9.93 to $-2.27 ; \mathrm{p}=0.002)$, and baseline ODI $(\boldsymbol{\beta}$ $0.44,95 \%$ CI 0.30 to $0.57 ; \mathrm{p}<0.001$ ).

In addition to errors in the text, we have corrected errors in Table 6 and in Supplemental Tables 1-3.

The corrected Table 6 is presented below. A corrected heading for column 2 as well as corrected values in the second and third columns are presented in bold typeface.

Corrections to Supplemental Tables 1-3 (available at https://thejns.org/doi/suppl/10.3171/2018.8.SPINE17913) also include changes to the second and third columns. Similar to Table 6, the heading of the second column in Supplemental Tables 1-3 has been changed from "Adjusted Odds Ratio (95\% CI)" to "Adjusted $\beta$ Coefficient" (95\% CI). In all supplemental tables, all values in this column

TABLE 6. Multivariate analysis assessing predictors of 12-month ODI following surgery for grade 1 lumbar spondylolisthesis

\begin{tabular}{|c|c|c|}
\hline Variable & $\begin{array}{c}\text { Adjusted } \beta \text { Coefficient } \\
(95 \% \mathrm{Cl})\end{array}$ & $\begin{array}{c}\mathrm{p} \\
\text { Value }\end{array}$ \\
\hline Addition of fusion to procedure & $-4.79(-9.28$ to -0.31$)$ & $0.04^{*}$ \\
\hline Age (yrs) & $-0.16(-0.33$ to 0.02$)$ & 0.09 \\
\hline Female & $-3.18(-6.47$ to 0.11$)$ & 0.06 \\
\hline Private insurance & $-0.38(-4.20$ to 3.44$)$ & 0.85 \\
\hline Diabetes mellitus & $0.59(-3.76$ to 4.93$)$ & 0.79 \\
\hline Coronary artery disease & $-0.13(-5.06$ to 4.80$)$ & 0.96 \\
\hline Depression & $0.63(-3.54$ to 4.79$)$ & 0.77 \\
\hline \multicolumn{3}{|l|}{ Dominant presenting symptom } \\
\hline Back pain dominant & $-0.44(-3.93$ to 3.04$)$ & 0.80 \\
\hline Leg pain dominant & $-1.83(-6.62$ to 2.95$)$ & 0.45 \\
\hline Back pain = leg pain & Reference & \\
\hline Motor deficit at presentation & $2.47(-1.33$ to 6.27$)$ & 0.20 \\
\hline Symptom duration $\geq 3$ mos & $7.87(-2.35$ to 18.09$)$ & 0.13 \\
\hline BMI & $0.47(0.21$ to 0.73$)$ & $0.001^{*}$ \\
\hline Education $\geq 4$ yrs of college & $-3.95(-7.38$ to -0.52$)$ & $0.02^{*}$ \\
\hline $\begin{array}{l}\text { Actively employed or em- } \\
\text { ployed \& on leave }\end{array}$ & $-6.10(-9.93$ to -2.27$)$ & $0.002^{*}$ \\
\hline MIS & $-2.52(-5.78$ to 0.75$)$ & 0.13 \\
\hline ODI, baseline & $0.44(0.30$ to 0.57$)$ & $<0.001^{*}$ \\
\hline NRS back pain, baseline & $0.46(-0.31$ to 1.22$)$ & 0.24 \\
\hline NRS leg pain, baseline & $-0.30(-0.98$ to 0.38$)$ & 0.38 \\
\hline EQ-5D, baseline & $-1.92(-11.54$ to 7.70$)$ & 0.70 \\
\hline
\end{tabular}

* Denotes a statistically significant relationship, alpha level 0.05 . 
have been changed. In the third column, " $p$ value," changes in value have also been made for "Dominant Presenting Symptom." This is also the case with Table 6. Of note, there are no changes in statistical significance.

We appreciate the opportunity to correct our errors. The article has been corrected online as of February 22, 2019.

Andrew K. Chan, MD

University of California, San Francisco, CA

INCLUDE WHEN CITING

Published online February 22, 2019; DOI: 10.3171/2019.1.SPINE17913a.

CAANS 2019, except where prohibited by US copyright law 